\title{
Solid variant of serous cystadenoma of the pancreas
}

Akira Yasuda, Hirozumi Sawai, Nobuo Ochi, Yoichi Matsuo, Yuji Okada, Hiromitsu Takeyama

Department of Gastroenterological Surgery, Nagoya City University Graduate School of Medical Sciences, Nagoya, Japan

Submitted: 15 November 2009

Accepted: 25 November 2009

Arch Med Sci 2011; 7, 2: 353-355

DOI: 10.5114/aoms.2011.22092

Copyright $\odot 2011$ Termedia \& Banach

\section{Abstract}

We describe a case of a solid variant of serous cystadenoma of the pancreas. The preoperative examination results led to a diagnosis of a nonfunctional pancreatic islet cell tumour, and the patient underwent a pylorus-preserving pancreaticoduodenectomy. The tumour was diagnosed as a solid variant of serous cystadenoma by histopathological examination. Solid variant of serous cystadenoma of the pancreas is difficult to diagnose preoperatively. More cases must be accumulated and investigated to obtain clues for accurate diagnosis.

Key words: solid serous cystadenoma, pancreas, pancreatic tumour.

\section{Introduction}

The solid variant of serous cystadenoma (SC) was first described by Perez-Ordonez in 1994 [1], and the tumour was defined as a solid tumour with cytological features of serous microcystic adenoma. Because solid variant SC is very rare, it is difficult to diagnose preoperatively. Magnetic resonance imaging (MRI) was reported to be useful for accurate diagnosis [2], but a definite consensus has not been reached. Here, we present our patient and review previous cases.

\section{Case report}

A 72-year-old woman was found to have a $2 \mathrm{~cm}$ tumour in the pancreatic head based on an ultrasound examination. Unenhanced computed tomography (CT) demonstrated a $2 \mathrm{~cm}$ low-density tumour in the pancreatic head (Figure $1 A$ ). It was strongly enhanced in the early phase of contrast-enhanced CT (Figure 1B), and the enhanced effect was prolonged to the late phase (Figure 1C). With MRI, it displayed a high intensity on the T2-weighted image (Figure 2). When we inspected the tumour using endoscopic ultrasonography (EUS), no cyst was recognized. Serum concentrations of glucagon and gastrin were normal. Therefore, we suspected a non-functional pancreatic islet cell tumour and performed a pylorus-preserving pancreaticoduodenectomy (PPPD). In the resected specimen, the tumour appeared clearly demarcated and solid, and it was $1.7 \times 1.3 \mathrm{~cm}$ in size. No cyst was recognizable with the naked eye (Figure 3). The tumour had histopathological features of SC (Figure 4). There was no evidence of malignancy. The final diagnosis was solid variant of SC of the pancreas. Written consent was obtained from the patient for publication of the study according to guidelines of the ethical committee of the Nagoya City University Hospital.
Corresponding author:

Hirozumi Sawai MD

Department of

Gastroenterological Surgery

Nagoya City

University Graduate

School of Medical Sciences

Kawasumi 1, Mizuho-cho

Mizuho-ku, Nagoya 4678601

Japan

Phone: +81 528538226

Fax: +81 528423906

E-mail:

sawai@med.nagoya-cu.ac.jp 

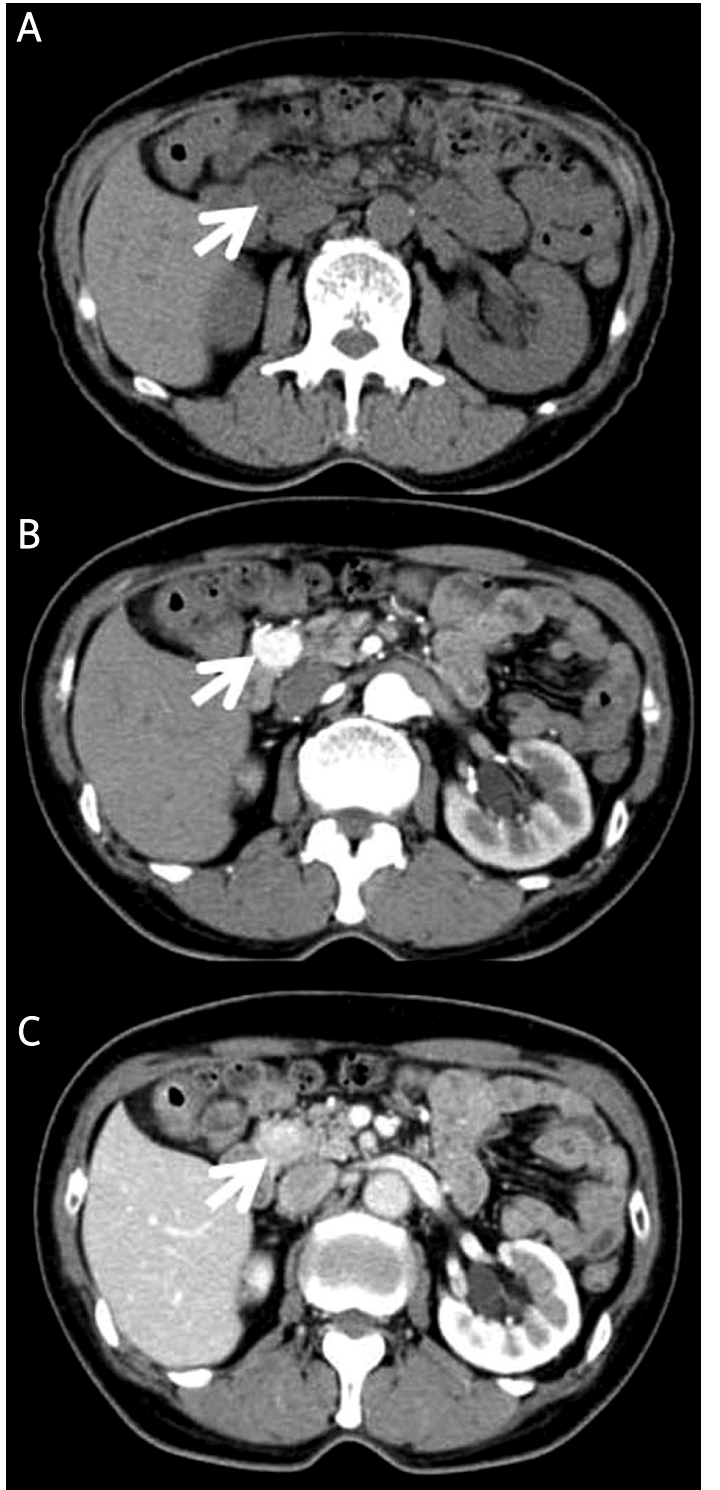

Figure 1. Unenhanced CT demonstrated a low-density tumour of $2 \mathrm{~cm}$ in the area between the pancreatic head and the second portion of the duodenum (A). The tumour was strongly enhanced in the early phase of contrast-enhanced CT (B), and the enhanced effect was prolonged to the late phase (C)

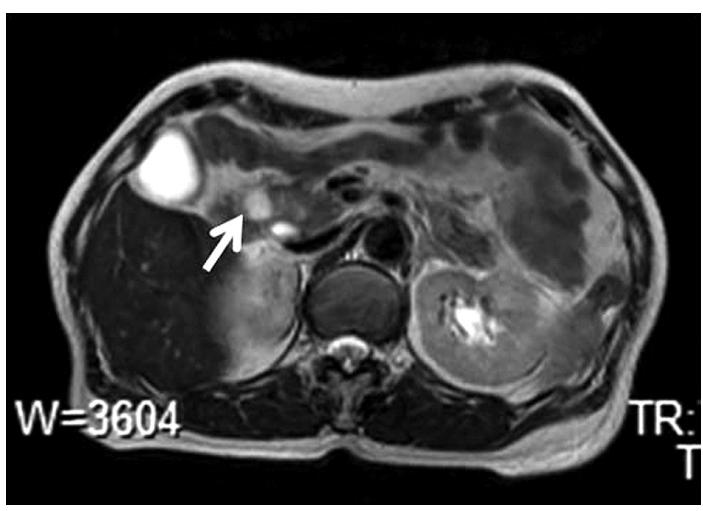

Figure 2. The tumour displayed a high intensity on the T2-weighted MRI image

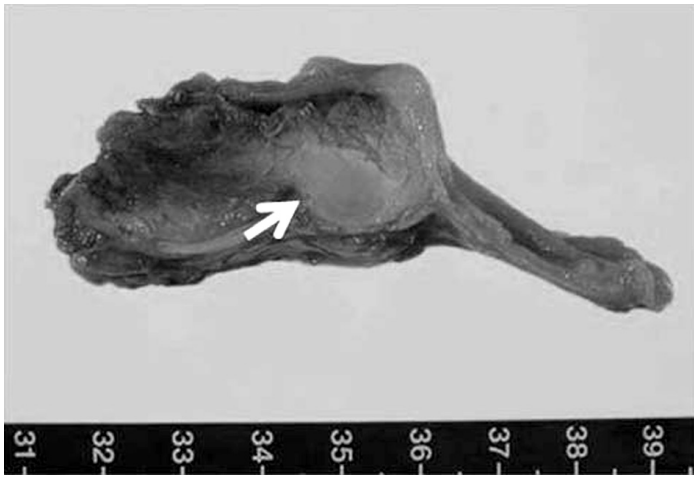

Figure 3. The tumour existed in the pancreatic head. It appeared clearly demarcated and solid, and it was $1.7 \times 1.3 \mathrm{~cm}$ in size. No cyst was recognized with the naked eye

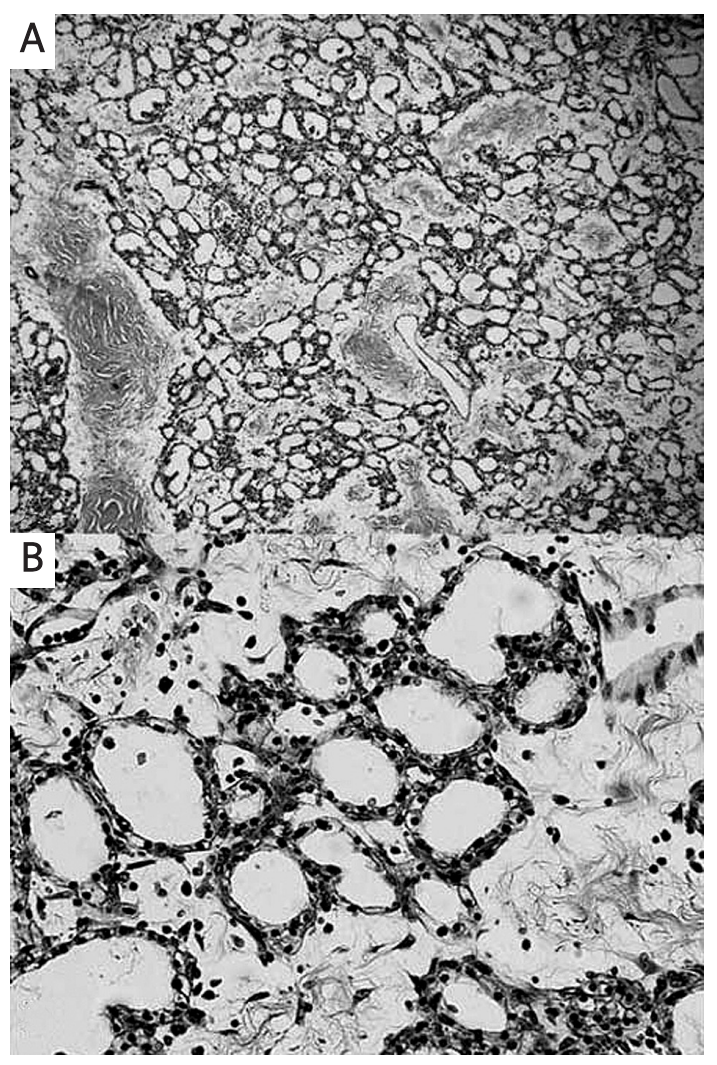

Figure 4. Histopathological examination of the tumour (haematoxylin/eosin stain). (A) Low magnification $(\times 40)$ and $(B)$ high magnification $(\times 200)$. Histopathological examination demonstrated that the tumour was surrounded by a wall, like a capsule, and was composed of a large number of small cysts. The walls of the cysts were cubic cells that had a small, round nucleus and pale-coloured cytoplasm. There was no evidence of malignancy

\section{Discussion}

Solid variant of SC is very rare; only eight cases, including our case, have been reported (Table I) [1-7]. As with the other pancreatic tumours, it is very difficult to make an accurate diagnosis of SC [8-11], because there are no characteristic symptoms; the 
Table I. Eight cases of solid variant of serous cystadenoma

\begin{tabular}{|ccccccccc|}
\hline Age & Sex & Symptom & Preoperative diagnosis & Location & Size $[\mathrm{cm}]$ & CT (U/E) & MRI (T1/T2) & Operation \\
\hline 70 & F & Abd. pain & Pancreatic islet tumour & Body & 4.0 & - & - & DP \\
\hline 50 & M & Abd. pain & Pancreatic islet tumour & Head & 2.5 & - & - & Unknown \\
\hline 58 & F & None & Pancreatic islet tumour & Body & 2.0 & - /High & - & DP \\
\hline 59 & F & Abd. pain & Solid SC & Body & 2.0 & Low/High & Low/High & DP \\
\hline 66 & M & None & Pancreatic islet tumour & Head & 4.0 & - /High & - & PPPD \\
\hline 74 & M & None & Pancreatic islet tumour & Body & 1.6 & - /High & - & Enucleation \\
\hline 62 & M & Abd. pain & Pancreatic islet tumour & Body & 4.2 & -/High & - & DP \\
\hline 72 & F & None & Pancreatic islet tumour & Head & 1.7 & Low/High & -/High & PPPD \\
\hline
\end{tabular}

Abd. pain-abdominal pain, SC - serous cystadenoma, CT (U/E) - CT (unenhanced/enhanced), PPPD - pylorus preserved pancreaticoduodenectomy, $D P$ - distal pancreatomy

identified cases were accompanied by non-specific abdominal pain or were discovered during examinations for other diseases. Distal pancreatomy or PPPD was performed based on tumour location, except for one enucleation. Solid variant of SC is difficult to diagnose preoperatively, and the tumour was diagnosed as an islet cell tumour in most of the previous cases. We also diagnosed the tumour preoperatively as a non-functional islet cell tumour because it was strongly enhanced on contrast-enhanced $\mathrm{CT}$, and no cystic lesion was observed. In the previous cases, the enhancing effect on CT was characteristic of solid serous adenoma, but this feature is also recognized in islet cell tumours and acinar cell tumours; therefore, it is not a definitive clue for diagnosis. Solid variant of SC was proposed as a preoperative diagnosis in only one previous case [2], in which it was reported that MR cholangiopancreatography (MRCP) was useful for diagnosis. The signal intensity of the pancreatic tumour remained higher than that of the cavernous haemangioma and equal to that of the hepatic cyst, which were detected incidentally on MRCP, and the investigators considered that the tumour was not a solid tumour, but a purely cystic tumour. According to these views, a solid type of SC was suspected. Magnetic resonance imaging was performed in our case as well, but no haemangioma or cyst was observed in the liver, so we could not observe the findings. Magnetic resonance imaging was not performed for the other 6 cases. We diagnosed the tumour preoperatively as a non-functional islet cell tumour and performed PPPD because approximately two-thirds of nonfunctional pancreatic islet cell tumours are malignant. However, a less invasive intervention, such as partial pancreatomy or observation without surgery, can be selected if the tumour is diagnosed accurately.

In conclusion, we encountered a rare pancreatic tumour, solid variant of SC, but it was difficult to diagnose preoperatively. Accurate diagnosis is important for deciding the surgical method, so more cases must be accumulated and investigated to obtain clues for accurate diagnosis.

\section{References}

1. Perez-Ordnez B, Naseem A, Lieberman P, Klimstra DS. Solid serous adenoma of the pancreas. The solid variant serous cystadenoma. Am J Surg Pathol 1996; 20: 1401-5.

2. Gabata T, Terayama N, Yamashiro M, et al. Solid serous cystadenoma of the pancreas: MR imaging with pathologic correlation. Abdom Imaging 2005; 30: 605-9.

3. Kosmahl M, Wagner J, Peters K, Sipos B, Kloppel G. Serous cystic neoplasms of the pancreas. An immunohistochemical analysis revealing alpha-inhibin, neuronspecific enolase, and MUC6 as new markers. Am J Surg Pathol 2004; 28: 339-46.

4. Yamaguchi M. Solid serous adenoma of the pancreas: a solid variant of serous cystadenoma or a separate desease entity. J Gastroenterol 2006; 41: 178-9.

5. Reese SA, Traverso LW, Jacobs TW, Longnecker DS. Solid serous adenoma of the pancreas. A rare variant within the family of pancreatic serous cystic neoplasms. Pancreas 2006; 33: 96-9.

6. Sanaka MR, Kowalski TE, Brotz C, Yeo CJ, McCue P, Palazzo J. Solid serous adenoma of the pancreas: a rare form of serous cystadenoma. Dig Dis Sci 2007; 52: 3154-6.

7. Stern JR, Frankel WL, Ellison EC, Bloomston M. Solid serous microcystic adenoma of the pancreas. World I Surg Oncol 2007; 5: 26.

8. Sawai H, Yasuda A, Ochi N, et al. TGF-beta regulates invasive behavior of human pancreatic cancer cells by controlling Smad expression. Arch Med Sci 2007; 3: 185-91.

9. Araszkiewicz A, Zozulińska-Ziółkiewicz D, WieruszWysocka B. Insulinoma in a patient with long lasting type 2 diabetes. Arch Med Sci 2009; 5: 486-8.

10. Roehrig $\mathrm{S}$, Wein A, Albrecht $\mathrm{H}$, et al. Palliative first-line treatment with weekly high-dose 5-fluorouracil as 24h-infusion and gemcitabine in metastatic pancreatic cancer (UICC IV). Med Sci Monit 2010; 16: CR124-31.

11. Giaginis C, Katsamangou E, Tsourouflis G, et al. Peroxisome proliferator-activated receptor-gamma and retinoid $X$ receptor-alpha expression in pancreatic ductal adenocarcinoma: Association with clinicopathological parameters, tumor proliferative capacity, and patients' survival. Med Sci Monit 2009; 15: BR148-56. 